\title{
Needle Exchange and the HIV Epidemic in Vancouver: Lessons Learned from 15 years of research
}

\author{
Elaine Hyshka ${ }^{1,2}$, Steffanie Strathdee ${ }^{4}$, Evan Wood ${ }^{2,3}$, and Thomas Kerr ${ }^{2,3}$ \\ ${ }^{1}$ Addiction and Mental Health Research Lab, School of Public Health, University of Alberta \\ ${ }^{2}$ British Columbia Centre for Excellence in HIV/AIDS, University of British Columbia \\ ${ }^{3}$ Department of Medicine, University of British Columbia \\ ${ }^{4}$ Department of Medicine, University of San Diego School of Medicine
}

\begin{abstract}
During the mid-1990s, Vancouver experienced a well characterized HIV outbreak among injection drug users (IDU) and many questioned how this could occur in the presence of a high volume needle exchange program (NEP). Specific concerns were fuelled by early research demonstrating that frequent needle exchange program attendees were more likely to be HIV positive than those who attended the NEP less frequently. Since then, some have misinterpreted this finding as evidence that NEPs are ineffective or potentially harmful. In light of continuing questions about the Vancouver HIV epidemic, we review 15 years of peer-reviewed research on Vancouver's NEP to describe what has been learned through this work. Our review demonstrates that: 1) NEP attendance is not causally associated with HIV infection, 2) frequent attendees of Vancouver's NEP have higher risk profiles which explain their increased risk of HIV seroconversion, and 3) a number of policy concerns, as well as the high prevalence of cocaine injecting contributed to the failure of the NEP to prevent the outbreak. Additionally, we highlight several improvements to Vancouver's NEP that contributed to declines in syringe sharing and HIV incidence. Vancouver's experience provides a number of important lessons regarding NEP. Keys to success include refocusing the NEP away from an emphasis on public order objectives by separating distribution and collection functions, removing syringe distribution limits and decentralizing and diversifying NEP services. Additionally, our review highlights the importance of context when implementing NEPs, as well as ongoing evaluation to identify factors that constrain or improve access to sterile syringes.
\end{abstract}

\section{Keywords}

needle exchange programs; injection drug use; HIV/AIDS; policing; Vancouver

\section{(C) 2012 Elsevier B.V. All rights reserved.}

Send correspondence to: Thomas Kerr, PhD, Director, Urban Health Research Initiative, B.C. Centre for Excellence in HIV/AIDS, University of British Columbia, St. Paul's Hospital, 608-1081 Burrard Street, Vancouver, B.C., V6Z 1Y6, Canada, Tel: 604-806-9116, Fax: (604) 806-9044, uhri-tk@ cfenet.ubc.ca.

Publisher's Disclaimer: This is a PDF file of an unedited manuscript that has been accepted for publication. As a service to our customers we are providing this early version of the manuscript. The manuscript will undergo copyediting, typesetting, and review of the resulting proof before it is published in its final citable form. Please note that during the production process errors may be discovered which could affect the content, and all legal disclaimers that apply to the journal pertain. 


\section{INTRODUCTION}

An estimated 15.9 million people worldwide inject drugs and approximately 3 million people who inject drugs (IDUs) are estimated to be HIV positive (Mathers et al., 2008). Injection drug use accounts for approximately 5-10\% of HIV infections globally and approximately $30 \%$ of HIV infections outside Sub-Saharan Africa (Mathers et al., 2010; UNAIDS, 2008). Recognizing this, the World Health Organization, the United Nations Office of Drug Control and the Joint UN Programme on HIV/AIDS have endorsed nine interventions for the prevention, treatment and care of HIV/AIDS in IDUs (WHO, UNODC \& UNAIDS, 2009). Needle exchange programs (NEPs) are one of these interventions.

NEPs provide sterile syringes and other injection equipment to IDUs; additional health services or referrals are also typically available (Vlahov, Robertson \& Strathdee, 2010). Numerous studies in diverse contexts have established the effectiveness of NEPs in reducing the borrowing and lending of used syringes, and in reducing the incidence of HIV infection amongst IDUs (Bastos and Strathdee, 2000; Des Jarlais 2000; Wodak \& Cooney, 2006; Ksobiech, 2003; Vlahov, Robertson, \& Strathdee, 2010). NEPs have also been shown to promote entry into addiction treatment (Brooner et al., 1998; Heimer, 1998; Strathdee et al., 1999; Strathdee et al., 2006). Several studies have found that NEPs do not increase drug use (Burring, 1991; Normand, Vlahov, \& Moses, 1995; Vlahov et al. 2001) or incite youth to start injecting drugs (Marx, Brahmbhatt, Beilenson, et al., 2001). Moreover, NEPs have not been shown to increase numbers of publicly discarded syringes (Doherty, Junge, Rathouz, et al., 2000), crime (Marx, Crape, Brookmeyer et al., 2000), or high risk social networks (Schechter, Strathdee, Cornelisse, et al. 1999; Lamothe, Bruneau, Franco, et al., 1998). Yet despite the established effectiveness of NEPs, they must be implemented to scale to achieve population level reductions in HIV incidence. Unfortunately, although NEPs are present in 82 countries that are home to approximately $80 \%$ of the estimated global IDU population, few countries have sufficient NEP coverage to effectively control HIV transmission (Mathers et al., 2010).

Although a large body of scientific evidence has established the effectiveness of NEPs, this form of intervention remains controversial and under-utilized, particularly in Eastern Europe, Asia and the United States (Des Jarlais et al., 2010; Mathers et al., 2010; Smith, Bartlett, \& Wang, in press). These problems persist despite international guidelines recommending NEPs as an essential HIV prevention program (WHO, UNODC \& UNAIDS, 2009). The failure to widely implement NEPs and bring these programs to scale reflects a longstanding emphasis on drug law enforcement as the primary response to illicit drug use. However, lingering misbeliefs about NEPs' negligible or even iatrogenic effects have also contributed to this problem (Buchanan, Shaw, Ford \& Singer, 2003). These beliefs have been in part fuelled by early research undertaken in settings where NEPs were first implemented.

During the 1980s, Vancouver, Canada experienced a significant increase in injection drug use rates. In response, a large NEP was implemented in 1988 (Bardsley, Turvey, \& Blatherwick, 1990). However, an early study published in AIDS in 1997 by Strathdee and colleagues titled "Needle exchange is not enough: lessons from the Vancouver injecting drug use study" revealed high HIV prevalence and incidence and continued needle sharing amongst frequent NEP attendees. This study and Vancouver's experience with NEP was repeatedly cited as rationale for opposing NEPs (American Journal of Public Health, 2000; Bellm, 1999; Bruneau \& Schecter, 1998; Schechter et al., 1999). As recently as 2005, the Strathdee et al. (1997) paper was cited by a US congressional representative calling for cuts in funding to international aid agencies that distributed sterile syringes (Wood et al. 2007). Controversy around NEP persists in the United States. In December 2011, the US Congress 
reinstated a ban on federal needle exchange program funding (originally ended in 2009 by President Obama) as part of new spending legislation (Taylor, 2011).

In light of the remaining controversy around NEPs in general, and the Vancouver NEP in particular, we review 15 years of research examining Vancouver's experience with NEP to unpack how an explosive HIV epidemic could occur alongside one of North America's largest and most established NEPs. We highlight subsequent research on the association between frequent needle exchange attendance and HIV serostatus, and augment this analysis by reviewing additional epidemiological and ethnographic research on the impact of NEP policies and law enforcement practices on access to sterile syringes. We conclude by detailing recent NEP policy changes in Vancouver and the associated impacts on rates of syringe sharing and HIV incidence among IDUs.

\section{BACKGROUND}

More than one third of Vancouver's estimated 13,500 IDUs are concentrated in a lower income neighbourhood know $\mathrm{n}$ as the Downtown Eastside (DTES), which borders major tourism and business districts and is characterized by poor living conditions and significant public disorder (McInnes, et al., 2009; Miller, et al., 2007). In 2009, the DTES had approximately 4401 single room occupancy units. A typical single room occupancy unit consists of one small room with no private bathroom or cooking facilities (City of Vancouver, 2010). Over the past decade and at any given time, approximately $50 \%$ of Vancouver's IDUs resided in a single room occupancy unit or other unstable housing arrangement, and 10\% were outright homeless (Urban Health Research Initiative [UHRI], 2009). In addition to thousands of single room occupancy units, the DTES is also home to a street-level survival sex work economy, and a substantial proportion of the city's estimated 1500 female sex workers reside there (McInnes, et al., 2009). Finally, the DTES remains Canada's largest public illicit drug market, despite a number of concentrated police operations targeting street-level buyers and sellers (Werb, Wood, Small, et al., 2008; Wood, Spittal, Small, et al., 2004). Street-level dealing and public injection are common occurrences in the neighbourhood (Wood \& Kerr 2006; UHRI, 2009).

Similar to other North American port cities, heroin injection was first documented in Vancouver during the late 1960s (Wood \& Kerr, 2006a). In 1988, Vancouver opened one of North America's first NEPs, which was supplemented by legal pharmacy sales of sterile syringes. Initially, the City of Vancouver and the Federal Ministry of Health agreed to fund the NEP to address growing rates of injection drug use in the DTES (Bardsley, Turvey \& Blatherwick, 1990; Hankins, 1998). The program was implemented cautiously with the federal government emphasizing the importance of minimizing any public disorder associated with the NEP. This emphasis continued when the province assumed financial responsibility for the NEP in 1992.

As such, up until 2002, Vancouver's NEP had an explicit policy of one-for-one syringe exchange, which tied clean syringe distribution to used syringe collection. The rationale for the exchange policy was threefold: 1) emphasis was placed on reducing public disorder including minimizing inappropriately discarded syringes in the DTES and surrounding areas; 2 ) it was believed that the process of exchange promoted face-to-face contact between outreach staff and IDUs and facilitated health service referrals; and 3) syringe exchange limits were thought to curtail the practice of IDUs selling clean syringes for profit, which was discouraged. Irrespective of the validity of these concerns, the emphasis on syringe exchange rather than distribution would have important implications for the availability of sterile syringes in the DTES (Hankins, 1998; Kerr et al., 2010; Kuyper et al., 2006; Spittal et al., 2004). 
Administered and run by the Downtown Eastside Youth Activities Society, the NEP included a fixed site needle exchange located in the heart of the DTES with initial trading limits of two syringes per day or 14 per week (Bardsley, Turvey, \& Blatherwick, 1990; Spittal et al., 2004). The NEP exchanged 127806 syringes in its first year. Two years later, a mobile exchange van was added to cover evenings when the fixed site was closed, and exchange limits were increased to allow IDUs to trade one used syringe for two clean syringes in an effort to keep up with demand. Individuals with health statuses (e.g. HIV seropositivity) that made them more likely to experience injection risk were allowed to exchange at twice the regular limit. By 1993, the NEP was exchanging over a million syringes a year (Archibald, Ofner, Strathdee et al., 1998). During this initial period of NEP operation, HIV incidence in the DTES was considered to be low and stable (Strathdee et al. 1997), although Hankin (1998) notes that initial resistance to NEP evaluation resulted in very limited HIV surveillance during this period.

This situation changed dramatically by 1994, when a number of factors - including the deinstitutionalization of the mentally ill, a lack of social housing, and a marked increase in the availability of powder cocaine - combined to produce a dual epidemic of injection drug use and HIV infection that culminated in one of the highest HIV incidence rates documented in the developed world (Strathdee et al, 1997; Wood \& Kerr, 2006a). Between 1993 and 1994, the proportion of Vancouver IDUs testing newly HIV positive grew from 2 to $7 \%$ (Archibald et al., 1997). Data from an early case-control study examining this increase found that frequent NEP attendees were engaged in a number of risk behaviours (such as syringe borrowing) and more likely to be frequent cocaine injectors (Archibald et al., 1998; Strathdee et al., 1997). This finding was in line with reports of a shift from heroin to cocaine as the main illicit drug in the DTES. Whereas IDUs typically injected heroin 2-4 times per day, IDUs injecting cocaine could inject upwards of 20 times per day due to the drug's relatively short half-life (Bourgois \& Bruneau, 2000; Tyndall et al., 2003). Accordingly, demand for syringes increased significantly and the Vancouver NEP limits were doubled from 2 syringes to 4 syringes per day or 28 per week ( 3 per mobile van visit), and a second van was added in 1993. In response to rising HIV prevalence rates, public health officials increased the NEP budget significantly and by 1995 a third van had been added and the exchange limits were again doubled. That year the NEP exchanged 1815480 syringes (Spitall et al. 2004, p. 37). The NEP exchanged 2.3 million syringes in 1996 and more than 2.5 million syringes in 1997 (Strathdee et al., 1997; City of Vancouver, 1998).

Strathdee et al. reported observational data from the newly established Vancouver Injection Drug Users Study (VIDUS) cohort in 1997. Data from the ongoing VIDUS cohort study is referred to throughout this paper; as such, a brief description of the methods is provided (see Wood et al., 2002a for a detailed methods description). VIDUS is an open prospective cohort, which began in May 1996. Participants are recruited through street-based outreach or self-referral, and are eligible to participate if they have injected illicit drugs at least once in the past month, reside in the Greater Vancouver region and provide written informed consent. The cohort includes approximately 1000 individuals who provide blood samples and complete interviewer-administered questionnaires at baseline and semi-annually.

Strathdee et al. 's (1997) initial sample included 1006 VIDUS participants of which 81\% reported frequent NEP attendance. The authors estimated the baseline HIV prevalence at $23.2 \%$ (95\% CI, 20.6-25.8), of whom 58\% were previously aware of their seropositive status. In terms of syringe sharing, 39\% of HIV-negative and 39\% of HIV-positive IDUs in their sample reported receptive and distributive syringe sharing respectively. Using multiple logistic regression, the authors found that attending an NEP more than once a week independently predicted HIV-positive serostatus, and this association persisted after adjusting for age, gender, frequency of injecting, drug most frequently injected, etc. (Table 
1). Of the 257 participants who tested HIV-negative at baseline and attended a 6-month follow-up, 24 seroconverted resulting in an estimated HIV incidence rate of 18.6 per 100 person-years (95\% CI, 11.1-26.0). Furthermore, 23 out of the 24 seroconverters reported that the NEP was their primary source for sterile syringes, and 5 out of 24 reported difficulty accessing syringes. However, the limited number of initial HIV seroconversions in the study did not allow for sufficient statistical power to fully explore this relationship (Strathdee et al., 1997; Drucker et al. 1998). In terms of coverage, Strathdee et al. (1997) estimated that Vancouver's NEP would have to exchange 5-10 million syringes per year to meet IDU demand and called for the program's further expansion. They concluded that the NEP was an important cornerstone of HIV prevention, but it alone was insufficient for preventing HIV incidence, and called for increased funding for other health and drug treatment services in Vancouver (p. F63). This conclusion echoed concerns raised elsewhere in Canada regarding the insufficiency of NEPs alone for controlling the spread of HIV/AIDS amongst IDU (Bruneau et al. 1997; Hankins 1998).

Vancouver's injection drug use problem - and the apparent failure of its NEP - gained media attention worldwide and generated interest from a variety of stakeholders, including the US Drug Enforcement Agency (S.A. Strathdee, personal communication, October 19, 2011). The contemporaneous publication of similar research from Montreal fueled the controversy further. Bruneau et al. (1997) prospectively followed 974 HIV seronegative participants and found that those who attended the NEP at baseline were 1.7 times more likely to seroconvert during follow -up. They also reported a positive association between exclusive NEP use and seroconversion. The authors attributed the rate of HIV infection amongst NEP attendees to serodiscordant network formation. However, this conclusion was criticized as "highly speculative" (Lurie, 1997, p. 1004) and was not substantiated in subsequent ethnographic and epidemiologic investigations (Bourgois \& Bruneau, 2000; Lamothe et al., 1998).

Following the release of Strathdee et al. (1997)'s findings, the situation in the Downtown Eastside was declared a public health emergency. Approximately $\$ 7 \mathrm{M}$ in federal and provincial funding was allocated to expand access to drug treatment, VCT and the NEP in the DTES. By February of 1997, Vancouver's exchange maximums had been increased to 14 syringes per day or 98 per week and the NEP evolved into a 24-hour operation, which included fixed sites, mobile vans and foot patrols (Spittal et al., 2004). Secondary exchanges - smaller, decentralized needle exchange points-were permitted to operate in the single room occupancy hotels and other venues to further meet the needs of IDU. The NEP went on to exchange approximately 2.4 million syringes in 1998, 2.9 million syringes in 1999, and 3.5 million syringes in 2000 (Small et al., 2008) - numbers well short of the 5-10 million annually Strathdee et al. (1997) recommended for full coverage. It would take years for Vancouver's HIV outbreak among IDUs to stabilize.

\section{EXPLAINING THE ASSOCIATION BETWEEN HIV SEROCONVERSION AND NEP ATTENDANCE}

International reaction to the Vancouver and Montreal studies was swift. Strathdee was approached by the DEA after presenting the findings at the Conference on Retroviruses and Opportunistic Infections in January 1997 and asked for the yet -to-be published AIDS paper (S.A. Strathdee, personal communication, October 19, 2011). Both the US Office of National Drug Control and several members of Congress interpreted Strathdee et al.'s (1997) publication as evidence that NEPs promote the spread of HIV among IDUs. Additionally, the US Drug Czar, General Barry McCaffery cited the Canadian findings as evidence that NEPs were "terrible drug policy, terrible social policy, and terrible law enforcement policy" (cited in Bourgois \& Bruneau 2000, p. 331) and the Office of National Drug Control Policy sent a task force to Vancouver. (S.A. Strathdee, personal 
communication, October 19, 2011). Strathdee also testified before Congress twice on this subject, and the 1997 paper was entered into the Congressional record with rhetoric that concluded that the NEP had failed. Resultantly, Bruneau and Schechter (1998) published and Op-Ed in the New York Times in an attempt to clarify US officials' misinterpretation of their findings. Despite this and other attempts at clarification the US government opted to continue its ban on federal fun ding for NEPs in 1998.

The Canadian studies also prompted a highly politicized academic debate (see Bruneau \& Franco 1998; Fisher \& Bigelow, 1998; Hahn, Moss, \& Vranizan, 1998; Lowndes \& Alary, 1998; Lurie 1997; Lurie 1998; Lurie \& Drucker, 1997; Moss \& Hahn 1999; and Moss 2000 for examples) in which a number of researchers published comments or interpretations of the findings. Many of those speculating about the observed relationships between NEP attendance and HIV seropositivity concurred with Strathdee et al. (1997)'s suggestion that NEP may attract higher-risk users, such that observed relationships could be attributable to selection effects (Bluthenthal, et al. 2000; Des Jarlais \& Friedman, 1998; Drucker et al., 1998; Hagan et al., 2000; Vlahov \& Junge, 1998; Lurie, 1997). However, some researchers took the findings as evidence that NEPs may not be effective interventions against HIV/ AIDS in some contexts (Fisher \& Bigelow, 1998; Moss \& Hahn, 1999; Moss 1999). Finally, some have suggested that comparisons between NEP attendees and non-attendees are inappropriate because the latter may have had economic means to access sterile syringes through pharmacy sales and/ or secondary syringe exchange (Bluthenthal et al., 2000; Vlahov \& Junge, 1998).

In response to the controversy and debate, the Vancouver authors published a follow-up study investigating the relationship between NEP attendance and HIV seroconversion in the VIDUS cohort in 1999. Schechter et al. (1999) examined whether HIV seroconversion was causally associated with the NEP either through network formation between serodiscordant IDUs or an increase in risk behaviours after attending the NEP. Data was collected from 870 IDUs who were seronegative at baseline, of which 64 seroconverted during the 15-month study period. 47 of these seroconversions occurred amongst frequent NEP attendees and 17 occurred amongst infrequent NEP attendees, a difference that was statistically significant. Frequent NEP attendees were more likely to report: unstable housing and hotel living, the DTES as their primary injection site, cocaine injection at least once per day, and needing assistance injecting (Table 2). Using Cox regression modeling the authors demonstrated that the number of new seroconversions "observed among frequent NEP attendees is close to that expected based on their higher risk profile at baseline" (p. F49). Furthermore, the authors did not find any evidence of network formation or increased risk behaviours resulting from NEP attendance. They concluded that there was no evidence supporting a causal association between NEP attendance and HIV incidence and that the observed relationship was indeed likely due to selection effects. Unfortunately, 47 seroconversions did not yield sufficient statistical power to fully examine the relationship and allow for adjustment of various potential confounders (Schechter et al., 1999).

A follow-up study to Schechter et al. (1999) analyzed data from 1996-2000 including an additional 61 VIDUS seroconversions, and demonstrated that frequent injection cocaine use, rather than NEP attendance, was the strongest predictor of HIV seroconversion among local IDUs [adjusted hazard ratio (95\% CI) 3.72(2.44-5.67) $p=0.001$ ]. Indeed, injection cocaine use predicted seroconversion in a dose-dependent fashion with participants who averaged more than three injections per day being seven times more likely to contract HIV (Tyndall et al., 2003, p. 887). Cocaine injection was also found to be an important risk factor for HIV infection in Montreal (Bourgois \& Bruneau, 1999; Brogly et al., 2000). In summary, the follow -up research conducted in response to Strathdee et al. (1997) provided no evidence to support a causal link between NEP attendance and HIV seroconversion, and rather indicated 
that the high risk profile of IDUs - including high rates of cocaine injection, syringe sharing, and inadequate NEP access likely played important roles in driving the Vancouver HIV/ AIDS epidemic. However, definitive answers concerning the HIV epidemic and the local NEP remained out of reach.

\section{CONTEXTUAL FACTORS CONTRIBUTING TO THE LIMITED EFFECTIVENESS OF VANCOUVER'S NEP}

Since the 1997 Strathdee et al. paper was first published, several epidemiological and ethnographic research studies have explored a number of contextual factors with potential to affect sterile syringes access in Vancouver. These factors can be divided broadly into two categories: NEP policy concerns and Vancouver policing practices.

\section{Vancouver needle exchange program policy concerns}

Many of the second-generation NEP studies in Vancouver pointed to various programmatic limitations associated with local NEP delivery. For example, Wood et al. (2002a) reported that ongoing high rates of syringe sharing were being driven by problems with access to sterile syringes (see Table 3). However, this study also revealed that IDUs who obtained their syringes exclusively from the NEP were significantly less likely to report syringe sharing. These findings pointed to the possibility that the Vancouver NEP was having a protective effect, rather than an iatrogenic one, for many of the IDUs who were able to access it regularly and that program expansion could potentially address ongoing HIV risk behaviour in this setting.

In a follow-up study examining VIDUS data collected between 2000-2001, Wood et al (2002b) revealed a number of programmatic deficiencies of the local NEP and helped reveal some reasons behind continued syringe-sharing. Among IDUs who primarily obtained their syringes from the fixed site NEP, the most common reasons given for experiencing difficulty accessing syringes were: fixed site being closed (71.0\%), missing the exchange van (36.2\%), and being out of the area where the NEP operates (31.9\%). Among IDUs who primarily obtained their syringes from the NEP exchange vans, missing the van (57.6\%), the fixed site being closed (51.5\%), being incarcerated (30.3\%) and being out of the area where NEP operate $(21.2 \%)$ were the most common reasons cited for experiencing difficulty accessing syringes (Figure 1).

Thus, a significant proportion of IDU experienced difficulty accessing sterile syringes due to the restrictive operating hours (8:00am to 8:00pm) of the NEP. This finding was further supported in subsequent research (Kerr et al., 2006; Kuyper et al., 2006; Wood et al., 2002b; Wood et al., 2003a;). Notably, the NEP's daylight operating hours were established in an effort to "reduce drug use in the vicinity of the exchange at night," implying "priority was given to making the program acceptable to local politicians and community members over optimizing syringe accessibility" (Wood and Kerr 2006b, p. 841). In addition to insufficient operating hours, Wood et al. (2002b) demonstrated that poor NEP coverage and service gaps also contributed to restricted access to sterile syringes amongst some IDUs. NEP mobile vans would visit areas with a high prevalence of injection drug use during the evening hours to supplement the fixed site. The number of exchange vans and routes in operation at any given time fluctuated with budget constraints and perceived demand (Spittal et al., 2004). Despite often being the only source for sterile syringes during the evening hours, many IDUs experienced trouble meeting up with the exchange van or spent their time in areas not covered by the fixed and mobile NEP sites.

In response to the NEP's restrictive operating hours, other policy concerns, and the ongoing problems with syringe access, a local drug user organization, the Vancouver Network of 
Drug Users (VANDU), set up an unsanctioned, user-run, evening needle exchange tent one block away from the fixed site (Figure 2). This NEP tent operated in the heart of the open drug scene between September 2001 and May 2002 (Kerr et al. 2006; Wood et al. 2003). The well-attended tent operated 7 nights a week until 4:00am for 9 months before being shut down by police (Small, Glickman, Rigter, \& Walter, 2010). An evaluation of the VANDU tent indicated that this NEP was meeting an unmet need by reaching IDUs with higher HIV risk profiles, including those who frequently injected cocaine, injected in public, or required assistance injecting, during the evening hours (Wood et al. 2003). This evaluation also revealed that the program was promoting safe syringe disposal.

A third NEP deficiency that contributed to restricted access to sterile syringes was the strict one-for-one or 'loaner' policies, which emphasized syringe exchange and used syringe recovery (Spittal et al., 2004; Kerr et al., 2006; Miller et al., 2006; Kuyper et al., 2006; Wood et al., 2003a). Spittal et al. (2004) examined this problem via ethnographic fieldwork in and around various NEP sites, including the mobile exchange vans, over a one-year period. They found that although an informal, widespread loaner system existed whereby NEP clients could access around 1-3 sterile syringes without providing used syringes for exchange, there remained a heavy emphasis on point-for-point exchange as demonstrated by nightly syringe counts and the significant pressure placed on workers to keep loaner numbers down. Moreover, the loaner system was contingent on worker's subjective assessment of client need and willingness to return used syringes. As one NEP worker put it

“...some drivers think these clients are just throwing them away. So they don't want to just hand them out. They tell clients to go get one... go find one in the alley. I don't do that. I'm not gonna make them crawl around in the alley looking for a rig in the dirt. That's just humiliating." (Spittal et al., 2004, p. 40)

A supplementary quantitative analysis demonstrated that $86.7 \%$ of participants in VIDUS reported receiving loaners from the needle exchange over a six-month period (Spittal et al., 2004, p. 41). Spittal et al. (2004) demonstrated considerable demand for sterile syringes amongst IDUs who had no used syringes to exchange, particularly amongst mobile van clients who were already more vulnerable to HIV risk. These findings suggest that the NEP might have better met demand through syringe distribution rather than exchange and that "in effect, clean syringes [were] being denied to those who need[ed] them most" (Spittal et al. 2004, p. 42; Wood et al., 2002a). Notably, despite a number of studies that have cited onefor-one exchange policies as problematic in constraining the availability of clean syringes (Heimer, Khoshnood, Biff, Guydish, \& Junge, 1998; Kral, Anderson, Flynn, \& Bluthenthal, 2004; Schechter et al. 1999; Spittal et al. 2004; Wood et al., 2001), Wood et al. (2002b) found that neither 'one-for-one-exchange' nor 'having no needles to exchange' emerged as a common issue for the 19\% (69) of NEP attendees in their sample who reported experiencing difficulty in accessing syringes. Additionally, Tyndall et al. (2002) found that Vancouver's restrictive exchange policy did not significantly restrict the number of syringes obtained per NEP visit, in comparison to Montreal where such a policy had been rescinded. This suggests that other program deficiencies (operating hours, site location, etc.) may have played a more significant role in driving the problems with syringe access in this setting.

\section{Policing practices}

In addition to NEP policy concerns, Vancouver Police Department policies contributed to constrained availability of sterile syringes in the DTES, unwillingness to carry sterile syringes, and increased injection risk behaviours, such as syringe-sharing. Several studies have examined the impact of police 'crackdowns' on IDUs (Kerr et al., 2005; Small et al., 2006; Wood et al., 2003a; Wood et al., 2003c; Wood et al., 2004). A crackdown is a period of large-scale, intensive police activity targeting a particular illegal activity (Sherman, 
1990). In the DTES, crackdowns have generally aimed to disrupt the open retail drug market and interrupt drug use and drug use-related crime (Wood et al. 2004). However, existing evaluations indicate that rather than decrease illegal drug use, police crackdowns tend to displace drug activity to neighbouring areas and thereby disrupt access to public health programs, including NEP (Aitken, Moore, Higgs, Kelsall, \& Kerger, 2002; Best, Strang, Beswick, \& Gossop, 2001; Small et al., 2006; Wood et al., 2003; Wood et al., 2004).

Wood et al. (2004) examined VIDUS data from January - June 2003. Beginning in April 2003, 50 additional officers were deployed in a DTES crackdown that resulted in more than 236 trafficking charges laid against 162 individuals (p. 1551). Consistent with other studies (Aitken, Moore, Higgs, Kelsall, \& Kerger, 2002; Best, Strang, Beswick, \& Gossop, 2001; Shannon et al. 2008; Small et al., 2006; Wood et al., 2003), Wood et al. (2004) found that the police crackdown in the DTES resulted in the displacement of drug use to neighbouring areas (p.1554), and decreased attendance at local NEPs. Moreover, another study (Figure 3) found that a police operation was associated with a $27 \%$ reduction in NEP attendance in the DTES (Wood et al., 2003c).

Additional ethnographic research undertaken has demonstrated that increased police presence associated with crackdowns in Vancouver served to increase a number of conditions and behaviours with potential to increase risk among IDUs, such as:

unwillingness to carry sterile syringes (Small et al., 2006), increased borrowing and lending of syringes (Kerr et al., 2005), improper syringe disposal (Small et al., 2006), being rushed/ less cautious while injecting (Small et al., 2006), accidental syringe sharing (Small et al., 2006), and decreased access to health and social services (Wood et al. 2003a; Small et al. 2006). This anecdote from Small et al.'s (2006) interviews with IDUs is but one example of the heightened injection risk scenarios associated with increased police presence

"We were in the alley getting ready to fix. I was with my fixing partner, Tommy. I'm not sure if he has AIDS - but he is HIV+ for sure. I had just loaded the rig with my dope and the water. Tommy had just finished fixing his when all of a suddenboom! A cop car pulls around the corner. So I dropped my rig, well actually I hid it in the side of the dumpster where that hollow is-I put it in there. And then without me realizing it, Tommy hid his in the same place. So the cops stopped and jacked us up. They asked our names and questioned us about what we were doing. So after the jack up they left and we got back to business. I reached into the hiding spot and grabbed my rig. What I thought was my rig. And I stuck it into my arm and realized there was no dope in it. It wasn't my rig! In the confusion I ended up using his rig because we tried to hide them from the cops." (p. 89)

In addition to crackdowns, other police practices contributed to restricted availability of sterile syringes and increased risky injecting amongst IDUs. Werb et al. (2008) reported on the impact of discretionary policing practices whereby police confiscate illegal drugs and injecting equipment in the absence of a formal arrest. In a sample of 465 active IDUs drawn from VIDUS, 130 participants (28\%) reported being stopped, searched or detained by police without arrest within the previous six months, of which $51 \%$ had syringes confiscated. Among the participants who reported having syringes confiscated, $6 \%$ indicated that they immediately borrowed a used syringe after their encounter with police.

In summary, the available evidence indicates that a number of policing practices restricted access to sterile syringes and contributed to increased risky injection practices in Vancouver. These contextual factors were often rooted in the prioritization of public order over IDU health outcomes. This was apparent in the police department's motivation for crackdown initiatives and discretionary policing tactics. Additionally, NEP program deficiencies such as restricted operating hours, service gaps, and point -for-point exchange/loaners were often 
a result of a desire to reduce public injection, disperse IDUs in the evening, and prevent the inappropriate disposal of syringes. This emphasis on public order objectives helps explain how this particular HIV outbreak occurred in the presence of an established, high-volume NEP program.

\section{EXPLAINING THE ASSOCIATION BETWEEN HIV SEROCONVERSION AND NEP ATTENDANCE: PART II}

Ten years after the original Strathdee et al. (1997) article, Wood and colleagues (2007) had sufficient data on incident HIV infections in the VIDUS cohort to publish a research article that more fully unpacked the relationship between NEP attendance and HIV seroconversion. Building on Schechter et al. (1999), the authors examined data collected between May 1996 to December 2004. Multivariate analyses of 1035 IDUs who were HIV negative at baseline indicated that daily NEP attendees, when compared to non-daily NEP attendees, were more likely to: be female (OR $=1.8 ; 95 \%$ CI: 1.4-2.3), Aboriginal/American Indian (OR = 1.4; $95 \%$ CI: 1.0-1.9), in unstable housing ( $\mathrm{OR}=2.2 ; 95 \% \mathrm{CI}: 1.7-3.0)$, DTES residents (OR = 2.8; 95\% CI: 2.1-3.7), have unsuccessfully sought addiction treatment (OR $=1.8 ; 95 \%$ CI: $1.3-2.4)$, be involved in sex work ( $\mathrm{OR}=2.4 ; 95 \% \mathrm{CI}: 1.8-3.2)$, be daily heroin users ( $\mathrm{OR}=$ 3.3 ; 95\% CI: $2.5-4.3)$, be daily cocaine users ( $\mathrm{OR}=4.7$; 95\% CI: 3.6-6.3), and be "shooting gallery" users (OR $=1.8 ; 95 \%$ CI: 1.4-2.4) (all $p<0.05)$. Additionally, daily NEP attendees were less likely to be receiving methadone (OR $=0.3$; 95\% CI: $0.2-0.5)$. These findings supported earlier research demonstrating that frequent NEP attendees had higher risk profiles, which made them more vulnerable to contracting HIV (Schechter et al. 1999).

By December 2004, 133 of the 1035 HIV negative at baseline participants seroconverted. Using Cox proportional hazard regression analysis, Wood et al. (2007) examined the time to HIV infection for daily vs. non -daily NEP attendance amongst seroconverters. Unadjusted, the relative hazard of HIV seroconversion for daily vs. non -daily NEP attendees was 2.69 (95\% CI: $1.89-3.83 ; p<0.001$ ) (Figure 4). However, after adjusting for daily cocaine use, the relative hazard changed to 1.89 (95\% CI: 1.11-2.38; $p=0.013$ ). The authors then adjusted for variables significantly associated with HIV seroconversion (sex, ethnicity, unstable housing, DTES residency, syringe borrowing, requiring help injection, binge drug use, cocaine injection, "shooting gallery" attendance, sex trade involvement, and having an HIV-infected sex partner) and the relative hazard of HIV seroconversion for daily versus non -daily needle exchange attendance dropped to 1.41 (95\% CI, 0.95-2.09; $p=.088$ ) (Figure 5). The authors concluded that differential HIV incidence rates between daily and non -daily NEP attendees could be explained by the higher risk profiles of the former.

Despite the observational nature of Wood et al.'s (2007) study, their findings help counter persistent misinformation and controversy around NEPs that has been fuelled by research in Vancouver and elsewhere. Their results also further reinforce the idea that both individual and contextual factors played a major role in Vancouver's HIV/AIDS outbreak.

\section{PUTTING RESEARCH EVIDENCE INTO POLICY AND PRACTICE: CHANGES TO VANCOUVER'S NEP}

Aside from countering negative beliefs about NEPs, the epidemiological and ethnographic research reviewed above has also been used to inform policy and program changes to the way needle exchanges operate in the city of Vancouver. Although the provincial government has not always adequately supported Vancouver's NEP, between 2000 and 2002 and in consultation with the VIDUS investigators, they began a positive shift in NEP focus towards distribution rather than exchange (Kerr et al., 2010; Small et al., 2010). This shift echoed reforms which occurred in Montreal after 1997 (Bourgois \& Bruneau, 2000; Hankins 1998; 
Tyndall et al., 2002) and was achieved through a number of programmatic changes including: 1) removing NEP administration from DEYAS' purview and placing it under the local health authority (Vancouver Coastal Health); 2) separating the syringe distribution and collection functions; 3 ) decentralizing NEP services by increasing distribution sites; 4) diversifying syringe distribution methods (e.g. using foot patrols, SROs, etc.); and 5) removing all syringe distribution limits (British Columbia Centre for Disease Control, 2003; Kerr et al.2010; Spittal, et al. 2004).

The province also facilitated the involvement of a number of innovative, peer-run NEP services designed to access especially hard -to-reach IDU populations. One such program was the VANDU Alley Patrol needle exchange program. Here, volunteers patrolled the alleys and other public places in pairs, distributing sterile syringes, providing harm reduction education to IDUs, and collecting used syringes (Hayashi et al., 2010). Although the volunteers faced many challenges, including locating IDUs displaced by police activity, the program ran until 2005 (a similar peer -driven program picked up where it left off). A recent evaluation of the VANDU Alley Patrol program found that it "succeeded in reaching a subpopulation of local IDUs at a high risk of HIV infection" even during police crackdowns when drug use and IDUs were displaced into neighbouring areas (Hayashi et al., 2010, p. 420). Specifically, individuals who received syringes from the Alley Patrol program were likely to be unstably housed ( $\mathrm{AOR}=1.83 ; 95 \%$ CI: 1.39-2.40), frequent heroin injectors $(\mathrm{AOR}=1.31 ; 95 \% \mathrm{CI}: 1.01-1.70)$, frequent cocaine injectors $(\mathrm{AOR}=1.34,95 \% \mathrm{CI}: 1.03-$ 1.73 ), injecting in public (AOR $=3.07,95 \% \mathrm{CI}: 2.32-4.06$ ), and less likely to reuse needles $(\mathrm{AOR}=0.65,95 \% \mathrm{CI}: 0.46-0.92)$.

\section{Examining the impact of Vancouver's NEP policy changes}

To assess the effects of Vancouver's new NEP policy on HIV risk behaviour and HIV incidence, Kerr et al. (2010) looked at rates of syringe borrowing/lending, and HIV incidence amongst a prospective cohort of 1228 IDUs. Using a multivariate generalized estimating equations and Cox regression (Figure 6), they found that the period following the NEP policy changes was independently associated with a larger than $40 \%$ reduction in syringe borrowing [adjusted $\mathrm{OR}=0.57 ; 95 \% \mathrm{CI}=0.49,0.65$ ] and lending $[\mathrm{AOR}=0.52$; $95 \% \mathrm{CI}=0.45,0.60]$ and declining HIV incidence [adjusted hazard ratio $=0.13 ; 95 \%$ $\mathrm{CI}=0.06,0.31]$. Moreover they found an increase in participants reported use of nontraditional NEP sources, suggesting that the Vancouver policy changes were resulting in improved access to sterile syringes for IDUs.

It should be noted that the absolute number of syringes distributed by the NEP appears to have declined after the new policy changes took effect. The Vancouver NEP distributed approximately 3.3 million syringes in 2001, 2.7 million syringes in 2002, 2 million syringes in 2003, 2.2 million syringes in 2004, and 1.9 million in 2005. However, the number of syringes exchanged before 2003 should not be compared to the number of syringes distributed in 2003 or later, because the change in service providers (from DEYAS to Vancouver Coastal Health) resulted in a change in data collection methods (Buxton, 2005). Moreover, a decrease in syringe distribution could be attributable to other factors which caused a decrease in injection drug use, such as age effects, or a shift away from powder cocaine injecting towards crack cocaine smoking (Gilbert, Buxton and Tupper, 2011).

\section{CONCLUSION}

Our review of 15 years of research on needle exchange in Vancouver's DTES clarifies a number of misconceptions regarding the HIV epidemic among IDUs and the NEP in this setting. Specifically it demonstrates that the observed relationship between frequent NEP attendance and HIV positive status is best understood as reflecting the higher risk profile of 
those accessing NEP services. IDUs who used Vancouver's NEP during the late 1990s and early 2000s were not at increased risk of contracting HIV/AIDS because of their NEP attendance. Rather, the IDUs who frequented the NEP were more likely to contract HIV/ AIDS because of several characteristics, including frequent cocaine injection, which comprised a vulnerable risk profile.

If the NEP did not produce iatrogenic effects, why was it unable to prevent the HIV/AIDS outbreak? Answering this question definitively is difficult because unobserved confounding factors might explain the epidemic patterns that were observed. However this review suggests that a host of contextual factors, including NEP operating hours, NEP service gaps, one-for-one exchange policies, a lack of prevention and treatment services, as well as police crackdowns, closing of peer-run services, and other practices exacerbated the spread of HIV/ AIDS in the DTES by significantly constraining the availability of sterile syringes and promoting HIV risk behaviours such as syringe sharing. These challenges help explain why the NEP alone was unable to prevent the HIV/AIDS outbreak.

The response to these NEP challenges highlights a number of lessons, specific to Vancouver, which can be taken from our review. First, an emphasis on reducing public disorder rather than distributing sterile syringes to IDUs who needed them was ill-advised. This focus resulted in a number of NEP policy and program features that constrained the availability of sterile syringes in the DTES and motivated police practices that aimed to reduce drug use and public disorder without considering the potential impacts on public health. Second, shifting the focus of the NEP away from public order objectives by separating NEP distribution and exchange functions, and removing all distribution limits improved access to sterile syringes in the DTES. Third, further decentralizing NEP sites, promoting peer-run initiatives, and diversifying syringe distribution methods helped the NEP better access hard-to-reach populations of IDU with particularly high risk-profiles. Lastly, the involvement of people who use drugs in the delivery of NEPs can help extend the reach of conventional NEPs and thereby ensure that those at highest risk of HIV infection are being reached.

There are also several more universal lessons regarding NEP gleaned from Vancouver's experience. First, program staff, researchers and policymakers should pay considerable attention to local context when designing and implementing NEP. Understanding and anticipating how internal aspects (program policies, logistics, etc.) and external aspects (local IDU population characteristics, policing practices, drug markets, etc.) impact the NEP is crucial for success. Second, ongoing evaluation and monitoring of the NEP and its changing context using both quantitative and qualitative methods can identify factors that constrain and promote sterile syringe access. Third, those assessing the merits of an NEP as a public health intervention need to consider how implementation and local environment features impact on the program's ability to reach IDU and prevent the spread of HIV.

Thus, jurisdictions looking to expand NEPs to scale as a means to curtail HIV transmission associated with injection drug use might benefit from reviewing Vancouver's experience with NEP from the early days to its eventual expansion and overhaul. Irrespective of their undue controversy, NEPs represent an important tool in an arsenal of HIV prevention, drug treatment, and health services, and have the potential to drastically reduce HIV incidence if implemented effectively.

\section{Acknowledgments}

The authors thank Will Small, Tricia Collingham, Deborah Graham and Peter Vann for their research assistance. 


\section{References}

Aitken C, Moore D, Higgs P, Kelsall J, Kerger M. The impact of a police crackdown on a street drug scene: evidence from the street. International Journal of Drug Policy. 2002; 13:189-98.

Archibald CP, Ofner M, Strathdee SA, Patrick DM, Sutherland D, Rekart ML, Schechter MR, O'Shaughnessy MV. Factors associated with frequent needle exchange program attendance in injection drug users in Vancouver, Canada. Journal of Acquired Immune Deficiency Syndromes \& Human Retrovirology. 1998; 17(2):160-166. [PubMed: 9473018]

American Journal of Public Health. Discussion. 2000; 90:1385-1396.

Bastos FI, Strathdee SA. Evaluating effectiveness of syringe exchange programmes: current issues and future prospects. Social Science \& Medicine. 2000; 51:1771-1782. [PubMed: 11128265]

Bardsley J, Turvey J, Blatherwick J. Vancouver's needle exchange program. Canadian Journal of Public Health. 1990; 81(1):39-45.

Bellm J. Needle-exchange programmes are not the answer [Letter; Comment]. Lancet. 1999; 353:1657-1661. [PubMed: 10335785]

Best D, Strang J, Beswick T, Gossop M. Assessment of a concentrated high-profile police operation: no discernible impact on drug availability, price or purity. British Journal of Criminology. 2001; 41:738-45.

Bluthenthal RN, Kral AH, Gee L, Erringer EA, Edlin BR. The effect of syringe exchange use on highrisk injection drug users: A cohort study. AIDS. 2000; 14:605-611. [PubMed: 10780722]

Bluthenthal RN, Kral AH, Lorvick J, Watters JK. Impact of law enforcement on syringe exchange programs: A look at Oakland and San Francisco. Medical Anthropology. 1997; 18:61-83. [PubMed: 9458668]

Bourgois P, Bruneau J. Needle exchange, HIV infection and the politics of science: Confroting Canada's cocaine injection epidemic with participant observation. Medical Anthropology. 2000; 18:325-350.

British Columbia Centre for Disease Control (BCCDC). Communicable disease control: Needle exchange programs. BCCDC; Vancouver: 2003.

Brogly SB, Bruneau J, Vincelette J, Lamothe F, Franco EL. Risk behaviour change and HIV infection among injection drug users in Montreal. AIDS. 2000; 14(16):2572-2582.

Brooner R, Kidorf M, King V, Beilenson P, Svikis D, Vlahov D. Drug abuse treatment success among needle exchange participants. Public Health Reports (Washington, DC: 1974). 1998; 113(Suppl 1): 129-139.

Bruneau J, Lamothe F, Franco E, Lachance N, Desy M, Soto J, Vincelette J. High rates of HIV infection among drug users participating in neddle exchange programs in Montreal: results of a cohort study. American Journal of Epidemiology. 1997; 146:994-1002. [PubMed: 9420522]

Bruneau J, Lamothe F, Franco E. Drs. Bruneau, Lamothe and Franco reply. American Journal of Epidemiology. 1998; 148(7):714.

Bruneau, J.; Schechter, MT. New York Times. 1998 Apr 9. The politics of needles and AIDS. Op-Ed; p. A27

Buchanan D, Shaw S, Ford A, Singer M. Empirical science meets moral panic: An analysis of the politics of needle exchange. Journal of Public Health Policy. 2003; 24(3/4):427-444. [PubMed: 15015873]

Burring EC. Effects of Amsterdam needle and syringe exchange. Substance Use \& Misuse. 1991; 26(12):1303-1311.

Buxton, J. [Accessed on March 222012 ] Vancouver drug use epidemiology: Vancouver site report for the Canadian Community Epidemiology Network on Drug Use (CCENDU). 2005. from http://vancouver.ca/fourpillars/pdf/report_vancouver_2005.pdf

City of Vancouver. [Accessed on March 8 2012] Administrative report: Information on needle exchange programs in Vancouver. 1998. from http://vancouver.ca/ctyclerk/cclerk/980421/a12.htm

City of Vancouver. [Accessed on October 23 2011] 2009 Survey of low-income housing in the downtown core. 2010. from http://vancouver.ca/commsvcs/housing/pdf/2009survey.pdf

Des Jarlais DC. Research, politics, and needle exchange. American Journal of Public Health. 2000; 90(9):1392-1394. [PubMed: 10983194] 
Des Jarlais DC, Friedman SR. Fifteen years of research on preventing HIV infection among injecting drug users: What we have learned, what we have not learned, what we have done, and what we have not done. Public Health Reports. 1998; 113(Suppl 1):182-188. [PubMed: 9722823]

Des Jarlais DC, Arasteh K, McKnight C, Ringer M, Friedman SR. Syringe exchange, injecting and intranasal drug use. Addiction. 2010; 105(1):155-158. [PubMed: 19891668]

Doherty MC, Junge B, Rathouz P, et al. The effect of a needle exchange program on numbers of discarded needles: A 2-year follow-up. American Journal of Public Health. 2000; 90:936-939. [PubMed: 10846512]

Drucker E, Lurie P, Wodak A, Alcabes P. Measuring harm reduction: the effects of needle and syringe exchange programs and methadone maintenance on the ecology of HIV. AIDS. 1998; 12(Supplement A):S217-S230. [PubMed: 9633006]

Fisher DG, Bigelow C. Letter to the editor. American Journal of Epidemiology. 1998; 148(7):714-715. [PubMed: 9778180]

Gilbert, M.; Buxton, J.; Tupper, K. Decreasing HIV infections among people who use drugs by injection in British Columbia. Office of the Provincial Health Officer; 2011. from http://www.health.gov.bc.ca/library/publications/year/2011/decreasing-HIV-in-IDUpopulation.pdf

Hahn J, Moss A, Vranizan K. Letter to the editor. American Journal of Epidemiology. 1998; 148(7): 714. [PubMed: 9778179]

Hagan H, McGough JP, Thiede H, Hopkins SG, Weis NS, Alexander R. Volunteer bias in nonrandomized evaluations of the efficacy of needle-exchange programs. Journal of Urban Health. 2000; 77(1):103-112. [PubMed: 10741846]

Hankins CA. Syringe exchange in Canada: Good but not enough to stem the HIV tide. Substance Use \& Misuse. 1998; 33(5):1129-1146. [PubMed: 9596380]

Hayashi K, Wood E, Wiebe L, Qi J, Kerr T. An external evaluation of a peer-run outreach-based syringe exchange in Vancouver, Canada. International Journal of Drug Policy. 2010; 21:418-421. [PubMed: 20359877]

Heimer R. Can Syringe Exchange Serve as a Conduit to Substance Abuse Treatment? Journal of Substance Abuse Treatment. 1998; 15(3):183-191. 16/S0740-5472(97)00220-1. [PubMed: 9633030]

Kerr T, Small W, Buchner C, Zhang R, Li K, Montaner J, Wood Evan. Syringe sharing and HIV incidence among injection drug users and increased access to sterile syringes. American Journal of Public Health. 2010; 100(8):1449-1453.10.2105/AJPH.2009.178467 [PubMed: 20558797]

Kerr T, Small W, Peeace W, Douglas D, Pierre A, Wood E. Harm reduction by a "user-run" organization: A case study of the Vancouver Area Network of Drug Users (VANDU). International Journal of Drug Policy. 2006; 17:61-69.

Kral A, Anderson R, Flynn N, Bluthenthal RN. Injection risk behaviours among clients of syringe exchange programs with different syringe dispensation policies. Journal of Acquired Immune Deficiency Syndromes. 2004; 37(2):1307-1312. [PubMed: 15385739]

Ksobiech K. A meta-analysis of needle sharing, lending, and borrowing behaviors of needle exchange program attenders. AIDS Education and Prevention. 2003; 15(3):257-268. [PubMed: 12866837]

Kuyper LM, Kerr T, Li K, Hogg RS, Tyndall MW, Montaner JSG, Wood Evan. Factors Associated With Buying and Selling Syringes Among Injection Drug Users in a Setting of One of North America's Largest Syringe Exchange Programs. Substance Use \& Misuse. 2006; 41(6-7):883899.10.1080/10826080600668712 [PubMed: 16809177]

Lamothe, F.; Bruneau, J.; Franco, E., et al. New sharing partners encounter places among needle exchange attenders. Abstract 23187 presented at the XII International Conference on HIV/AIDS; Geneva, Switzerland. 1998.

Lowness CM, Alary M. Letter to the editor. American Journal of Epidemiology. 1998; 148(7):713714. [PubMed: 9778178]

Lurie P. Invited commentary: Le mystère de Montréal. American Journal of Epidemiology. 1997; 146(12):1003-1006. [PubMed: 9420523]

Lurie P. Dr. Lurie replies. American Journal of Epidemiology. 1998; 148(7):715-716. 
Lurie P, Drucker E. An opportunity lost: HIV infections associated with lack of a national needleexchange programme in the USA. The Lancet. 1997; 349(9052):604-608.

Marx MA, Crape B, Brookmeyer RS, et al. Trends in crime and the introduction of a needle exchange program. American Journal of Public Health. 2000; 90:1933-1936. [PubMed: 11111271]

Marx MA, Brahmbhatt $\mathrm{H}$, Beilenson $\mathrm{P}$, et al. Impact of needle exchange programs on adolescent perceptions about illicit drug use. AIDS Behavior. 2001; 5:379-386.

Mathers BM, Degenhardt L, Ali H, Wiessing L, Hickman M, Mattick RP, Myers B, et al. HIV prevention, treatment, and care services for people who inject drugs: a systematic review of global, regional, and national coverage. The Lancet. 2010; 375(9719):1014-1028.10.1016/ S0140-6736(10)60232-2

Mathers BM, Degenhardt L, Phillips B, Wiessing L, Hickman M, Strathdee SA, Wodak A, et al. Global epidemiology of injecting drug use and HIV among people who inject drugs: a systematic review. The Lancet. 2008; 372(9651):1733-1745.10.1016/S0140-6736(08)61311-2

McInnes CW, Druyts E, Harvard SS, Gilbert M, Tyndall MW, Lima VD, Wood E, Montaner JSG, Hogg RS. HIV/AIDS in Vancouver, British Columbia: a growing epidemic. Harm Reduction Journal. 2009; 6:5. [PubMed: 19265531]

Miller CL, Kerr T, Frankish JC, Spittal PM, Li K, Schechter MT, Wood E. Binge drug use independently predicts HIV seroconversion among injection drug users: Implications for public health strategies. Substance Use \& Misuse. 2006; 41:199-210. [PubMed: 16393742]

Miller CL, Kerr T, Strathdee SA, Li K, Wood E. Factors associated with premature mortality among injection drug users in Vancouver. Harm Reduction Journal. 2007; 4:1. [PubMed: 17201933]

Normand, J.; Vlahov, D.; Moses, LE. Preventing HIV Transmission: The Role of Sterile Needles and Bleach. Washington, DC: National Academy Press/National Research Council/Institute of Medicine; 1995.

Patrick DM, Tyndall MW, Cornelisse PGA, Li K, Sherlock CH, Rekart ML, Strathdee SA, et al. Incidence of hepatitis $\mathrm{C}$ virus infection among injection drug users during an outbreak of HIV infection. CMAJ. 2001; 165(7):889-895. [PubMed: 11599327]

Schechter MT, Strathdee SA, Cornelisse PGA, Currie S, Patrick DM, Rekart ML, O'Shaughnessy MV. Do needle exchange programmes increase the spread of HIV among injection drug users an investigation of the Vancouver outbreak. AIDS. 1999; 13(6):F45-F51. [PubMed: 10397556]

Shannon K, Rusch M, Shoveller J, Alexson D, Gobson K, Tyndall MW. and For the Maka Partnership. Mapping violence and policing as an environmental-structural barrier to health service and syringe availability among substance-using women in street-level sex work. International Journal of Drug Policy. 2008; 19(2):140-147. [PubMed: 18207725]

Sherman LW. Police crackdowns: Initial and residual deterrence. Crime and Justice. 1990; 12:1-48.

Small D, Glickman A, Rigter G, Walter T. The Washington needle depot: Fitting healthcare to injection drug users rather than injection drug users to healthcare: moving from a syringe exchange to syringe distribution model. Harm Reduction Journal. 2010; 7:1. [PubMed: 20047690]

Small W, Wood E, Buchner C, Fair B, Kerr T. Decline in needle exchange use in Vancouver, Canada coincides with the Australian heroin shortage. International Journal of Drug Policy. 2008; 19:291292. [PubMed: 18424114]

Smith K, Bartlett N, Wang N. A harm reduction paradox: Comparing China's policies on needle and syringe exchange and methadone maintenance. International Journal of Drug Policy. 2012 (In press, corrected proof). 10.1016/j.drugpo.2011.09.010

Spittal P, Small W, Wood E, Johnston C, Charette J, Laliberte N, O'Shaughnessy MV, Schecter MT. How otherwise dedicated AIDS prevention workers come to support state-sponsored shortage of clean syringes in Vancouver, Canada. International Journal of Drug Policy. 2004; 15(1):3645.10.1016/S0955-3959(03)00132-4

Strathdee SA, Celentano DD, Shah N, Lyles C, Stambolis VA, Macalino G, Nelson K, et al. Needleexchange attendance and health care utilization promote entry into detoxification. Journal of Urban Health. 1999; 76(4):448-460.10.1007/BF02351502 [PubMed: 10609594]

Strathdee SA, Patrick DM, Archibald CP, Ofner M, Cornelisse PGA, Rekart M, Schecter MT, O'Shaughnessy MV. Social determinants predict needle-sharing behaviour among injection drug users in Vancouver, Canada. Addiction. 1997; 92(10):1339-1347. [PubMed: 9489050] 
Strathdee SA, Patrick D, Currie S, Cornelisse PGA, Rekart ML, Montaner JSG, Schechter MT, O'Shaughnessy MV. Needle exchange is not enough: lessons from the Vancouver injecting drug use study. AIDS. 1997; 11(8):F59-F65. [PubMed: 9223727]

Strathdee SA, Ricketts EP, Huettner S, Cornelius L, Bishai D, Havens JR, Beilenson P, et al. Facilitating entry into drug treatment among injection drug users referred from a needle exchange program: Results from a community-based behavioral intervention trial. Drug and Alcohol Dependence. 2006; 83(3):225-232. 16/j.drugalcdep.2005.11.015. [PubMed: 16364566]

Taylor, A. Capitol Hill talks yield \$1T spending measure. Associated Press; 2011. from http://www.google.com/hostednews/ap/article/ALeqM5jrtliOm8mQIoqn118iCzpjtkjTOA? docId=5bab8c3af03440f0825af77dad3153b4

Tyndall MW, Bruneau J, Brogly S, Spittal P, O’Shaughnessy MV, Schechter MT. Satellite needle distribution among injection drug users: Policy and practice in two Canadian cities. Journal of Acquired Immune Deficiency Syndromes. 2002; 31:98-105. [PubMed: 12352156]

Tyndall MW, Currie S, Spittal P, Li K, Wood E, O’Shaughnessy MV, Schechter MT. Intensive injection cocaine use as the primary risk factor in the Vancouver HIV-1 epidemic. AIDS. 2003; 17:887-893. [PubMed: 12660536]

UNAIDS. [Accessed on October 23 2011] UNAIDS report on the global AIDS epidemic. 2008. from http://www.unaids.org.login.ezproxy.library.ualberta.ca/en/dataanalysis/epidemiology/ 2008reportontheglobalaidsepidemic/

UNAIDS. [Accessed on June 24 2011] UNAIDS report on the global AIDS epidemic. 2010. from http://www.unaids.org.login.ezproxy.library.ualberta.ca/globalreport/global_report.htm\#

Urban Health Research Initiative. [Accessed March 7 2012] Drug situation in Vancouver. 2009. from http://www.cfenet.ubc.ca/publications/drug-situation-vancouver-uhri-report

Vlahov D, Des Jarlais DC, Goosby E, Hollinger PC, Lurie PG, Shriver MD, Strathdee SA. Needle Exchange Programs for the Prevention of Human Immunodeficiency Virus Infection: Epidemiology and Policy. American Journal of Epidemiology. 2001; 154(12):S70-S77.10.1093/ aje/154.12.S70 [PubMed: 11744532]

Wodak A, Cooney A. Do needle syringe programs reduce HIV infection among injecting drug users: a comprehensive review of the international evidence. Substance Use \& Misuse. 2006; 41(6-7): 777-813.10.1080/10826080600669579 [PubMed: 16809167]

Werb D, Wood E, Small W, Strathdee S, Li K, Montaner J, Kerr T. Effects of police confiscation of illicit drugs and syringes among injection drug users in Vancouver. International Journal of Drug Policy. 2008; 19(4):332-338. [PubMed: 17900888]

Wood E, Kerr T. What do you do when you hit rock bottom? Responding to drugs in the city of Vancouver. International Journal of Drug Policy. 2006a; 17(2):55-60.10.1016/j.drugpo. 2005.12.007

Wood E, Kerr T. Needle exchange and the HIV outbreak among injection drug users in Vancouver, Canada. Substance Use \& Misuse. 2006b; 41(6-7):841-843.10.1080/10826080600669595 [PubMed: 16809174]

Wood E, Kerr T, Spittal PM, Small W, Tyndall MW, O'Shaughnessy MV, Schechter MT. An External Evaluation of a Peer-Run "Unsanctioned" Syringe Exchange Program. Journal of Urban Health. 2003a; 80(3):455-464.10.1093/jurban/jtg052 [PubMed: 12930883]

Wood E, Kerr T, Spittal PM, Tyndall MW, O’Shaughnessy MV, Schechter MT. The health care and fiscal costs of the illicit drug use epidemic: The impact of conventional drug control strategies, and the potential of a comprehensive approach. BC Medical Journal. 2003b; 45(3)

Wood E, Kerr T, Small W, Jones J, Schechter MT, Tyndall MW. The impact of police presence on access to needle exchange programs. Journal of Acquired Immune Deficiency Syndorme. 2003c; 34(1):116-117.

Wood E, Spittal PM, Small W, Kerr T, Li K, Hogg RS, Tyndall MW, Montaner JSG, Schechter MT. Displacement of Canada's larget public illicit drug market in response to a police crackdown. Canadian Medical Association Journal. 2004; 170(10):1551-1556. [PubMed: 15136548]

Wood, Evan; Lloyd-Smith, E.; Li, K.; Strathdee, SA.; Small, W.; Tyndall, MW.; Montaner, JSG., et al. Frequent needle exchange use and HIV incidence in Vancouver, Canada. The American Journal of Medicine. 2007; 120(2):172-179.10.1016/j.amjmed.2006.02.030 [PubMed: 17275459] 
Wood E, Tyndall MW, Spittal P, Li K, O’Shaughnessy M, Schechter MT. Perdictors of persistent high-risk syringe sharing during an ongoing HIV epidemic. Canadian Journal of Infectious diseases. 2001; 12(suppl B)

Wood E, Tyndall MW, Spittal PM, Li K, Hogg RS, Montaner JSG, O’Shaughnessy MV, Schechter MT. Factors associated with persistent high-risk syringe sharing in the presence of an established needle exchange programme. AIDS. 2002a; 16(6):941-943. [PubMed: 11919503]

Wood E, Tyndall MW, Spittal PM, Li K, Hogg RS, O’Shaughnessy MV, Schechter MT. Needle exchange and difficulty with needle access during an ongoing HIV epidemic. International Journal of Drug Policy. 2002b; 13(2):95-102.10.1016/S0955-3959(02)00008-7

World Health Organization, United Nations Office on Drugs Crime \& Joint United Nations Programme on HIV/AIDS. [Accessed on August 232011 ] WHO, UNODC, UNAIDS technical guide for countries to set targets for universal access to HIV prevention, treatment and care for injecting drug users. 2009. from

http://www.unodc.org/documents/hivaids/idu_target_setting_guide.pdf 
Figure 1a:

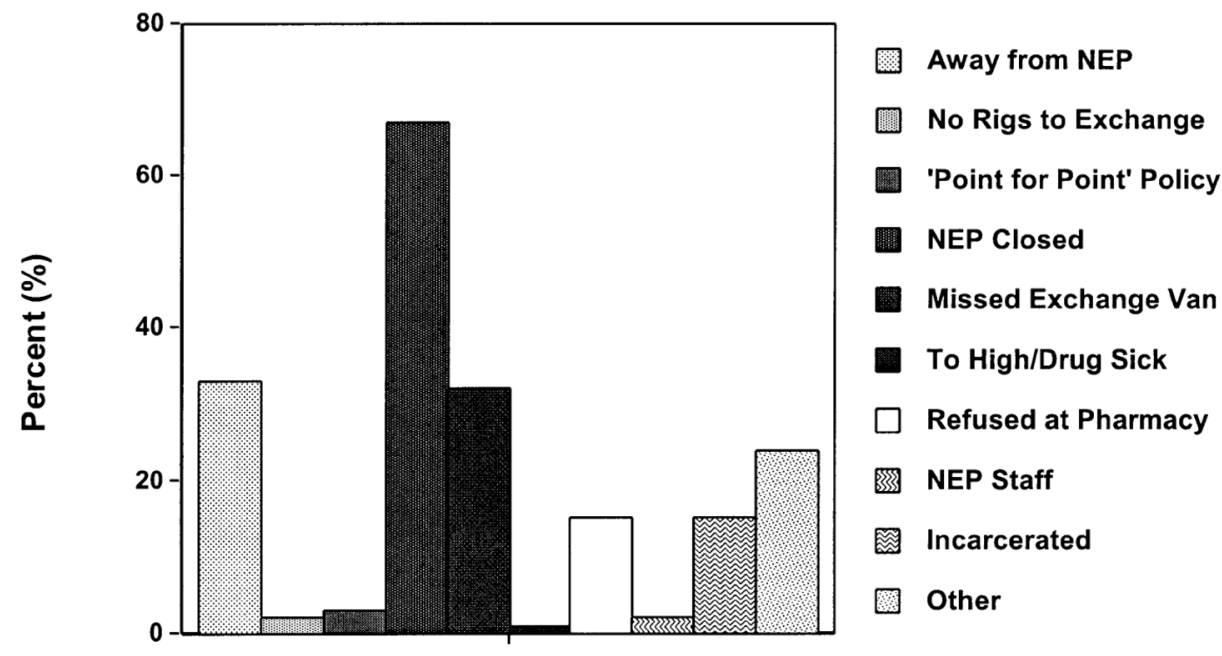

Figure 1b:

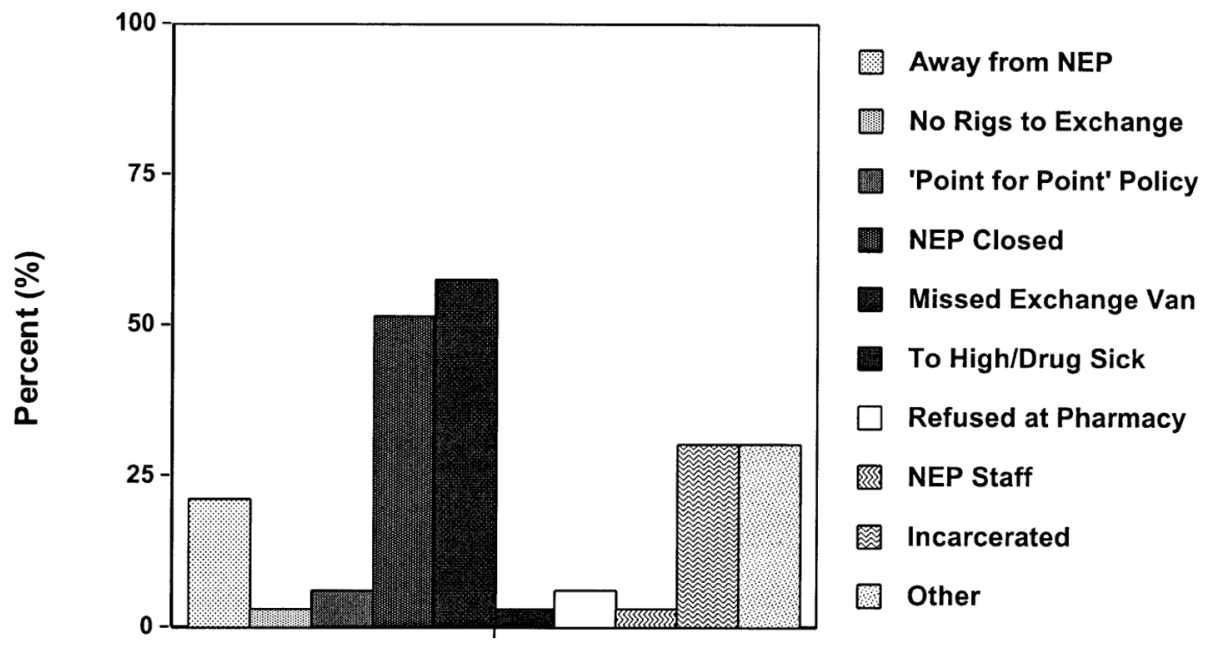

Figure 1.

Figure $1(a+b)$. Frequencies of responses to the question regarding why participants had difficulty accessing sterile needles among the 69 participants who acquired most of their needles from the fixed site exchange (1a) or from the vans (1b). Reprinted from Wood et al. (2002b). 


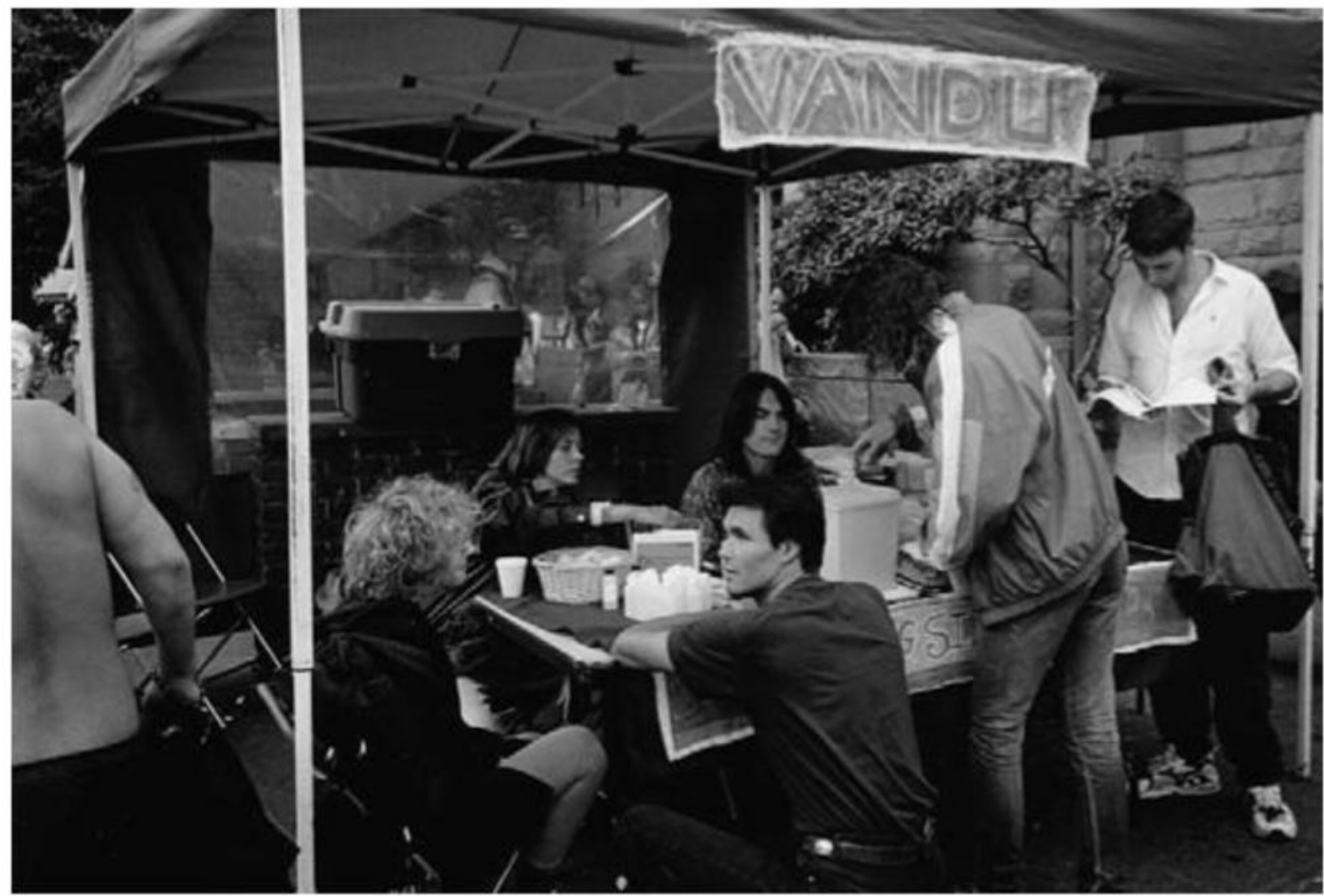

Figure 2.

the VANDU needle exchange table at the corner of Main and Hastings Streets. Reprinted from Kerr et al. 2006. 


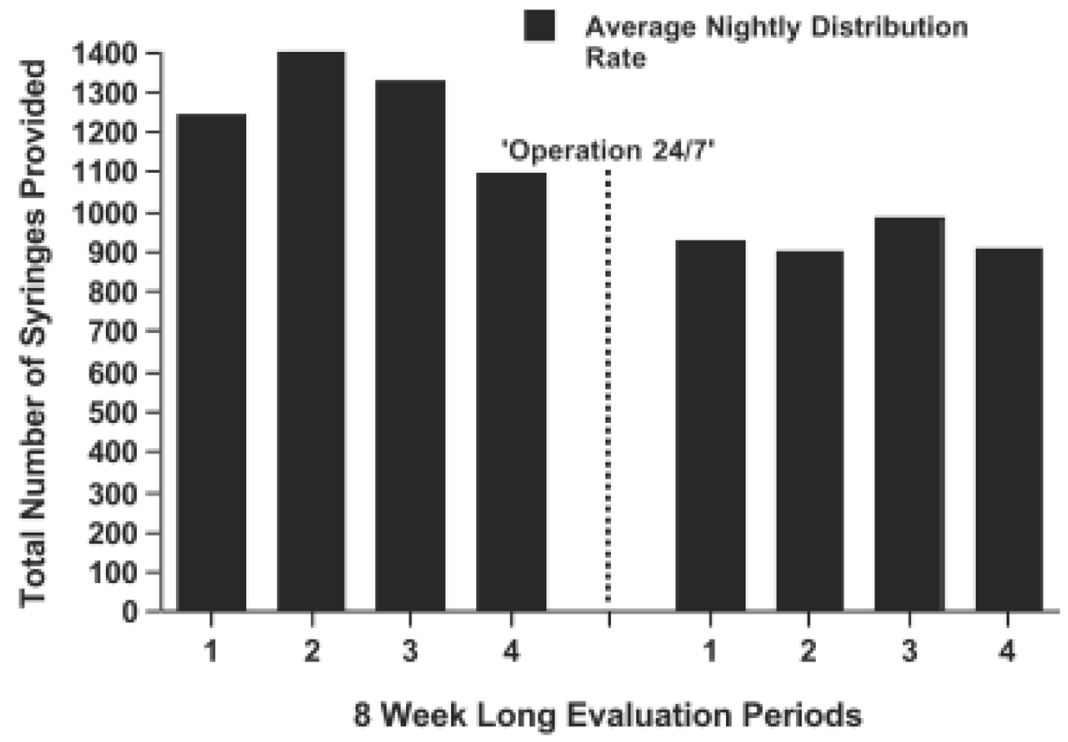

Figure 3.

Average number of sterile syringes providing during each 4-week period to and after operation 24/7. Reprinted from Wood et al. (2003c). 

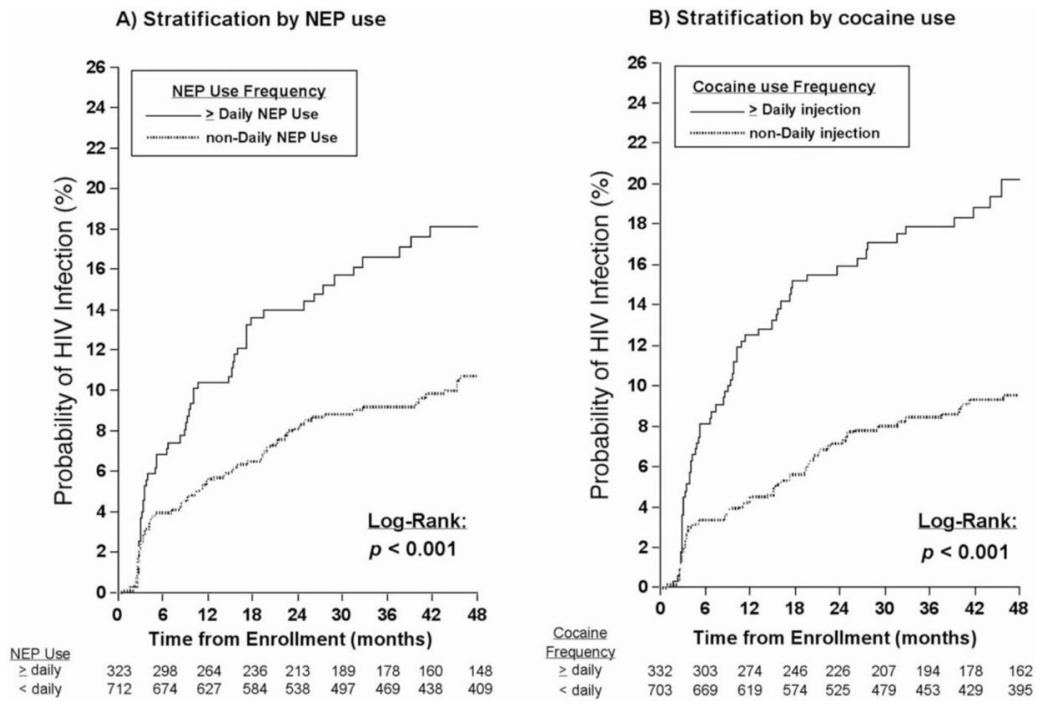

Figure 4.

The Kaplan-Meier cumulative HIV incidence rate among injection drug users stratified by daily NEP use and restricted to those that did and did not report daily cocaine injection at baseline. Reprinted from Wood et al. 2007. 


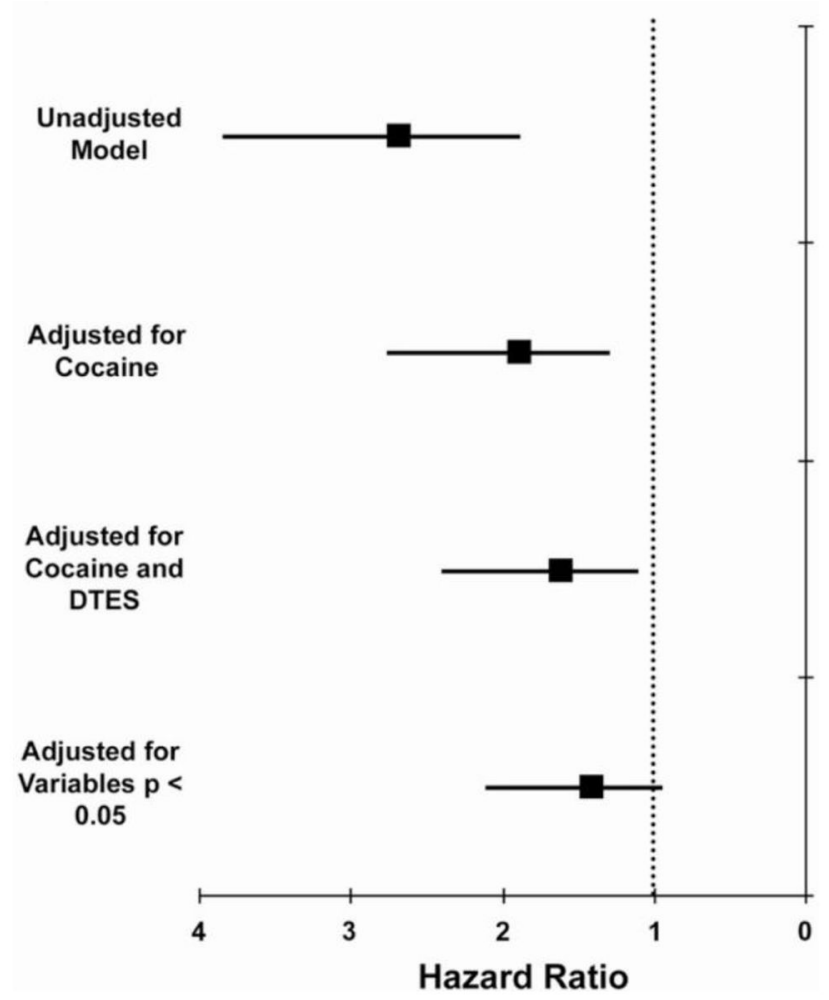

Figure 5.

Hazard ratios and 95\% CI for HIV infection associated with daily NEP use after the stepwise inclusion of potential confounders. Reprinted from Wood et al. (2007). 


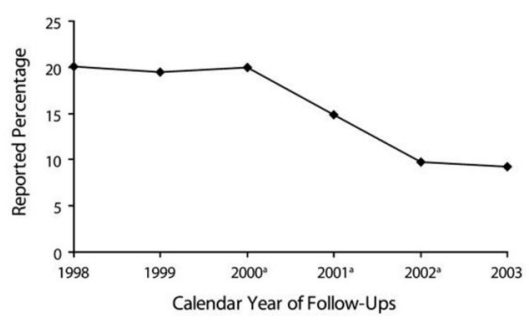

b

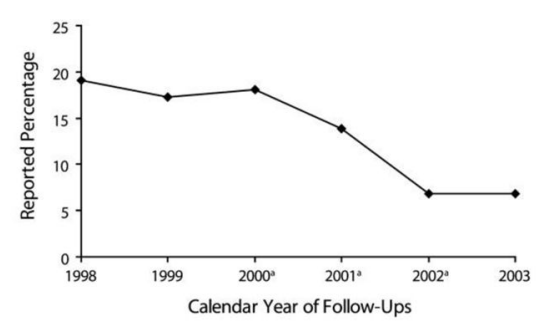

Figure 6.

Proportion of VIDUS participants reporting (a) syringe borrowing and (b) syringe lending: Vancouver, British Columbia, 1998-2003. Reprinted from Kerr et al. 2010. 


\section{Table 1}

Final multivariate logistic regression model predictors of HIV-positive serostatus at baseline among injecting drug users (IDU) in Vancouver. Reprinted from Strathdee et al. 1997

\begin{tabular}{lll}
\hline Variable & Adjusted odds ratio (95\% CI) & $\boldsymbol{P}$ \\
\hline Unstable housing $^{*}$ & $1.61(1.15-2.98)$ & 0.005 \\
Education (< high school) & $1.79(1.14-2.82)$ & 0.006 \\
Commercial sex $^{*}$ & $1.66(1.18-2.35)$ & 0.008 \\
Ever used borrowed needles & $1.49(1.04-2.14)$ & 0.03 \\
Inject with others * & $1.62(1.13-2.32)$ & 0.008 \\
Established injector ${ }^{\dagger}$ & $2.24(1.34-3.74)$ & 0.002 \\
Frequent NEP ${ }^{*}$ attendance (more than once per week) & $1.68(1.13-2.5)$ & 0.011 \\
\hline${ }^{*}$ Based on previous 6 months. & & \\
${ }^{\dagger}$ First injection >2 years previously. & & \\
NEP, Needle exchange programme. & &
\end{tabular}




\section{Table 2}

Comparison of frequent versus infrequent attendees at the Vancouver NEP with respect to risk behaviour profile at the baseline visit and follow -up duration odds ratio Kaplan-Meier HIV Incidence curves from enrolment to 15 months for frequent and infrequent NEP attendees. Reprinted from Schechter et al. (1999).

\begin{tabular}{|c|c|c|}
\hline Variable & Infrequent attendee $(n=289)$ & Frequent attendee $(n=405)$ \\
\hline Median age (years) & 37 & 35 \\
\hline Unstable housing & $188(65 \%)$ & $346(85 \%)$ \\
\hline Living in a hotel & $144(50 \%)$ & $272(68 \%)$ \\
\hline DTES as main injecting site & $183(63 \%)$ & $311(77 \%)$ \\
\hline Inject four or more times per day & $42(14 \%)$ & $171(42 \%)$ \\
\hline Inject heroin at least once per day & $69(24 \%)$ & $205(51 \%)$ \\
\hline Inject cocaine at least once per day & $62(22 \%)$ & $249(62 \%)$ \\
\hline Injecting in 'shooting galleries' & $66(23 \%)$ & $170(42 \%)$ \\
\hline Incarceration in past 6 months & $67(23 \%)$ & $154(38 \%)$ \\
\hline Involved in the sex trade & $47(16 \%)$ & $109(27 \%)$ \\
\hline Any illegal income (excluding sex trade) & $83(29 \%)$ & $176(44 \%)$ \\
\hline Currently enrolled in methadone treatment & $47(16 \%)$ & $34(8 \%)$ \\
\hline Pharmacy as primary needle source & $50(17 \%)$ & $6(1 \%)$ \\
\hline \multicolumn{3}{|l|}{ Person-semesters of follow-up } \\
\hline Prior to December 1996 & $149(23 \%)$ & $224(25 \%)$ \\
\hline January 1997-June 1997 & $241(38 \%)$ & $345(38 \%)$ \\
\hline After July 1997 & $248(39 \%)$ & $330(37 \%)$ \\
\hline
\end{tabular}

*Wilcoxon's rank sum test.

DTES, Downtown eastside. 